\title{
Technique for intragastric delivery of solutions: Application for self-administration of morphine and alcohol by rats
}

\author{
STANLEY G. SMITH, TOREEN E. WERNER, and W. MARVIN DAVIS \\ Department of Pharmacology, University of Mississippi, University, Mississippi 38677
}

\begin{abstract}
An esophageal method for intragastric self-administration of drugs by rats is presented. Included are descriptions of the surgical procedures for gastric cannulation by an esophageal approach and data from rats given opportunity to acquire intragastric self-administration behavior for $.3 \mathrm{mg} / \mathrm{kg} /$ injection of morphine sulfate solution or 50 or $10 \mathrm{mg} / \mathrm{kg} / \mathrm{injection}$ of ethyl alcohol solutions. The results indicated that for each drug, three out of four rats had acquired the behavior within 7 days. In other observations, it was found that cannulas remained functional yet at 4 months after surgery.
\end{abstract}

One of the more widely used methods for the experimental analysis of opiate or alcohol-taking behavior has been the oral self-administration technique (Kumar \& Stolerman, 1973; Nichols \& Davis, 1959; Nichols, Headlee, \& Coppock, 1956; Wikler, 1965; Woods, Ikomi, \& Winger, 1971). While this technique has been popular, it suffers from the fact that opiate or alcohol naive rats consistently avoid taking either drug orally. To achieve self-administration, behavior researchers have needed to establish physical dependence by injections, forced drinking regimens, or some type of induction procedure (e.g., Kumar, Steinberg, \& Stolerman, 1968; Mello, 1972; Nichols, Headlee, \& Coppock, 1956). While this enabled the eventual study of self-administration in physically dependent organisms, it prevented the analysis of initial acquisition of self-administration behavior by naive organism. The latter would be important in behavioral analysis by animal models as human drug-taking behavior does not usually originate from a baseline of physical dependence.

The method of intragastric (IG) self-administration offers an alternative which avoids problems encountered with oral methods. This procedure enables an animal to bypass oropharyngeal sensory receptors and self-infuse a drug directly into the stomach. Thus, it circumvents activation of the physiological mechanism responsible for opiate or alcohol aversion yet provides the same drug disposition chain as ordinary oral self-administration (i.e., stomach, intestine, venous circulation of the viscera, and systemic arterial circulation).

Two IG methods have been employed in the past for drug self-administration research. The first, using the abdominal approach, was originally applied by Kohn (1951) for stomach loading of nondrug solutions in unrestrained rats but was adapted to drug self-administration by Gotestam (1973) for medazepam

This work was supported by PHS Research Grants DA00018-07 and AA01217-01 and in part by the Research Institute of Pharmaceutical Sciences, School of Pharmacy, University of Mississippi. The authors wish to express appreciation to Dr. M. B. Howorth, Jr. for technical advice during development of the procedure. and morphine and by Marfaing-Jallat, Pruvost, and Le Magnen (1974) for alcohol. The second, using the nasopharyngeal approach, was developed by Epstein $(1960,1967)$ for analysis of nondrug reinforcers in the rat and was employed for alcohol self-administration in monkeys by Yanagita, Ando, Takahashi, and Ishida (Note 6).

Recently, a new IG technique using an esophageal approach was reported by Smith, Werner, and Davis (Note 1 ). This technique, with some further innovations (T. E. Werner, Note 5), has been found to avoid postoperative problems associated with the abdominal and/or nasopharyngeal procedures, i.e., excessive recovery time, infections, and deaths. Therefore, to demonstrate the new surgical procedure and the development of IG self-administration of an opiate (morphine) and alcohol, the following is presented.

\section{METHOD}

\section{Subjects}

Eight adult male Wistar rats, weighing $400-500 \mathrm{~g}$, were used as subjects. All subjects were drug naive at the start of the experiment. Water and food were available ad lib throughout. All subjects were housed individually.

\section{Apparatus}

Each rat was implanted with a chronic indwelling intragastric cannula which passed from the esophagus subcutaneously to an exit on the upper back, where it was attached to an external leather and metal saddle or harness. From the harness, the cannula system was attached to a length of needle tubing which led to a leakproof swivel at the top center of the chamber. The opposite end of the swivel was connected by vinyl tubing to an infusion pump which delivered $.092 \mathrm{ml}$ of $.9 \%$ saline solution, morphine sulfate solution, or ethyl alcohol solution in a 1-sec interval each time it was activated. The experimental chamber, a plastic cylinder of $24 \mathrm{~cm}$ height and $25 \mathrm{~cm}$ diam, contained a response lever, food, and water. Each chamber was lighted and enclosed within a ventilated sound-attenuated compartment. Leverpresses were registered on electromechanical counters, while all programming was accomplished automatically with relay circuitry.

\section{Surgical Procedure}

The subject was lightly anesthetized with methoxyflurane 


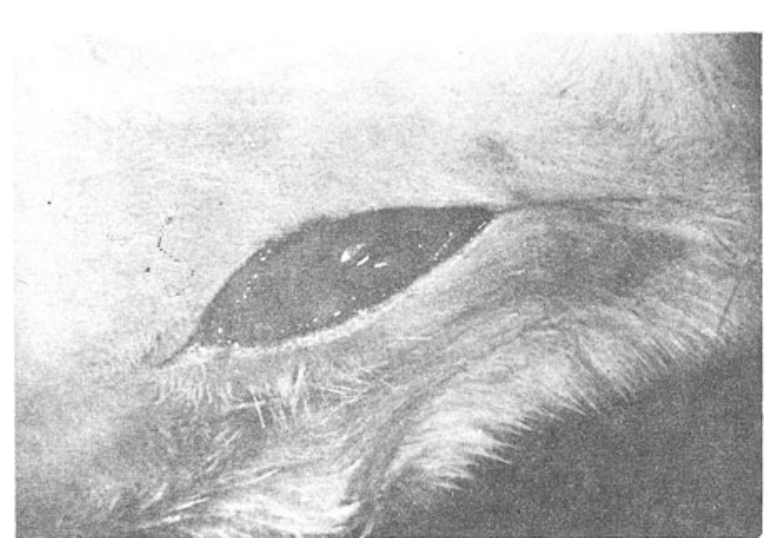

Figure 1. A $3-\mathrm{cm}$ midline skin incision for cannulation. The rat's head is at the upper right.

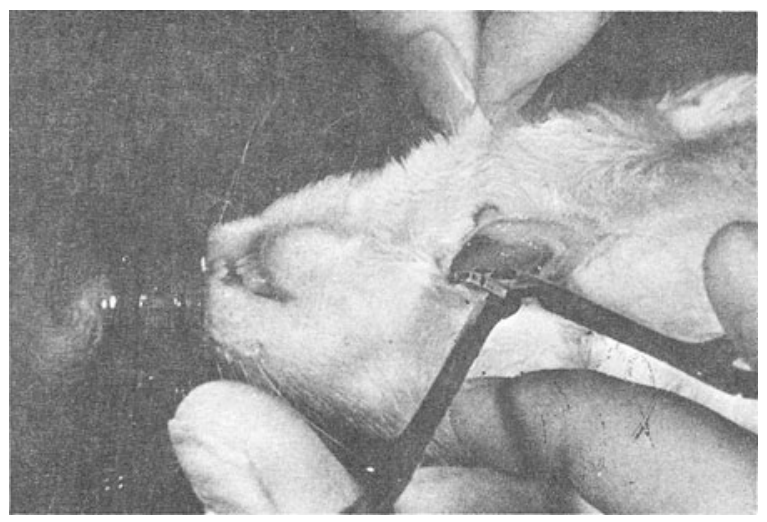

Figure 2. The beginning of a blunt dissection to expose the esophagus.

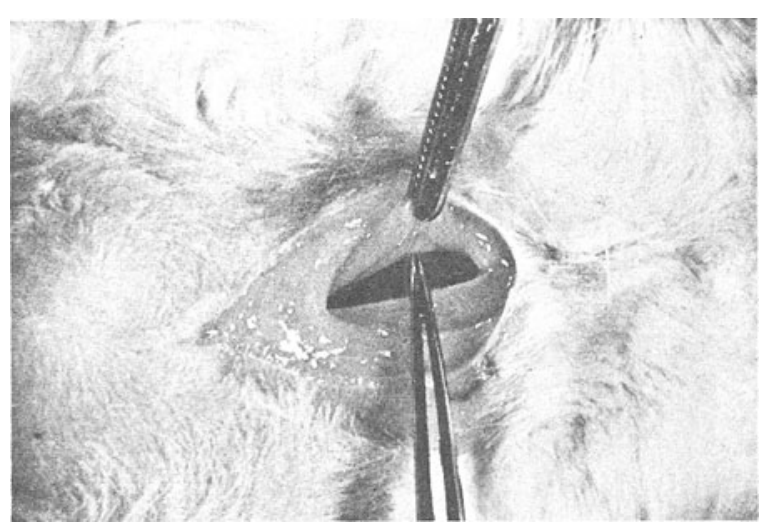

Figure 3. An incision made by the blunt dissection technique. The forceps at the top point to the esophagus. The rat's head is at the left.
(Metofane, Pitman-Moore) and shaved on the lower neck area and on the back of the neck (between ears and shoulders). The rat was then fully anesthetized for surgery with further methoxyflurane. A 3-cm skin incision was made on the midline of the throat with a scalpel (Figure 1). Surgical scissors may be more appropriate for persons not well practiced in surgical procedures. Care was taken not to cut into the chest muscle during the skin incision. Following the skin incision, blunt dissection (Figure 2) was used at the midline of the throat to penetrate the muscles to reach the esophagus (Figure 3). Blunt dissection was accomplished by first placing the closed surgical scissors points on the chest muscles, then opening them with slight downward pressure. This procedure was repeated, spreading the muscles apart until the trachea could be seen. The esophagus lies immediately below it. The esophagus was exposed, lifted gently with a trocar, and punctured with a 20-ga needle (Figure 4).

Medical grade silicone-rubber tubing $(.012 \mathrm{ft}$ ID by $.025 \mathrm{ft}$ OD, Silastic) was inserted $33 \mathrm{~cm}$ into the esophagus so that the tip rested just above the entrance to the stomach (Figure 5). The tubing was sutured to the tissue surrounding the esophagus and then to the neck muscle (Figure 6). The tubing was then passed subcutaneously around the neck to the back where it exited through a small skin incision (Figure 7). Following surgery, 50,000 units of procaine penicillin $\mathrm{G}$ were given intramuscularly. This procedure is relatively simple and requires only $48 \mathrm{~h}$ for postoperative recovery.

\section{Experimental Procedure I: Morphine}

The subjects were placed in the test chamber and attached to the injection system via their external harness. A 1-h period was then allowed for adaptation to the chamber. Following adaptation, a 10-h operant level was determined. During this time, each barpress was followed by a 1-sec intragastric infusion of $.092 \mathrm{ml}$ of saline. On each of the following 7 days, a 10-h acquisition period was run at the same time of day the operant level had been taken. All conditions were identical except that a dose of $.3 \mathrm{mg} / \mathrm{kg} /$ injection of morphine was substituted for saline.

\section{Experimental Procedure II: Alcohol}

The subjects were given an adaptation period followed by an operant baseline period with all contingencies identical to those for morphine. On the next 4 days, the subjects were given an opportunity to self-administer intragastric doses of $50 \mathrm{mg} / \mathrm{kg} /$ injection of ethyl alcohol. Two of the subjects were allowed an additional four sessions at $10 \mathrm{mg} / \mathrm{kg} /$ injection of ethyl alcohol.

\section{RESULTS}

The data for the subjects given access to morphine are shown in Figures 8 and 9. The number of infusions (Figure 8) and responses (Figure 9) during the morphine sessions both greatly exceeded those in the saline session for three of four rats. Thus, the resplts indicate that three out of four subjects acquired IG morphine self-administration behavior. The number of responses exceeded the number of infusions for most sessions because the 1-sec infusion duration allowed more than one response per infusion.

The results for IG self-administration of alcohol $(50 \mathrm{mg} / \mathrm{kg} /$ injection) are shown in Figures 10 and 11 . The number of infusions (Figure 10) and the number of responses (Figure 11) for alcohol sessions both exceeded those during the control saline session for three of four rats. Changing the two subjects that displayed the lowest number of responses (and infusions) to a dosage of 


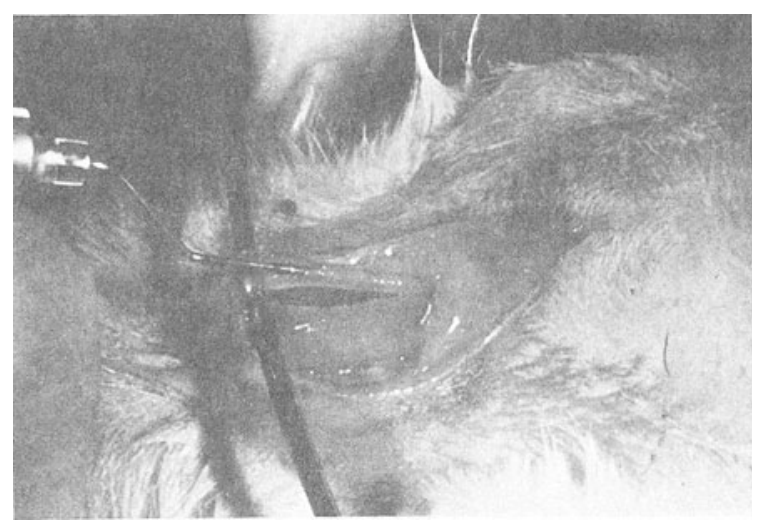

Figure 4. The esophagus is lifted with a trocar and positioned for puncture. A 20-ga needle bent as shown is used to puncture the esophagus. The rat's head is at the left.

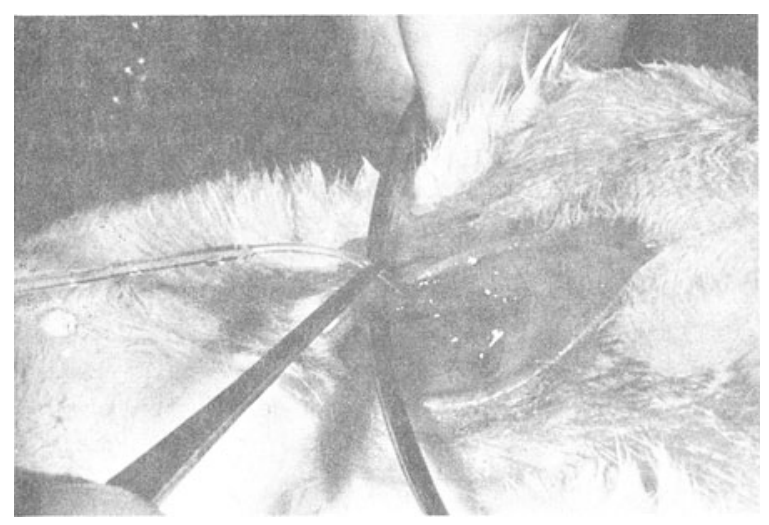

Figure 5. Cannula being inserted into the esophagus through the puncture made by a 20-ga needle. The rat's head is at the left.

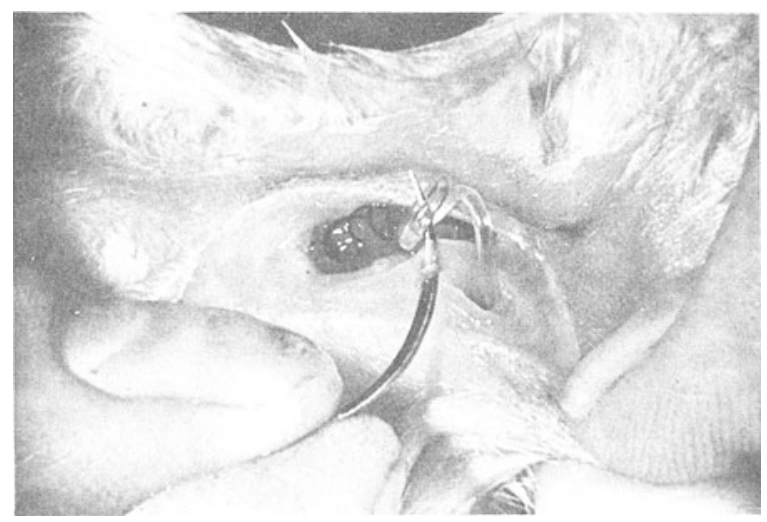

Figure 6. The cannula being tied to the neck muscles before exiting. The rat's head is at the upper left.

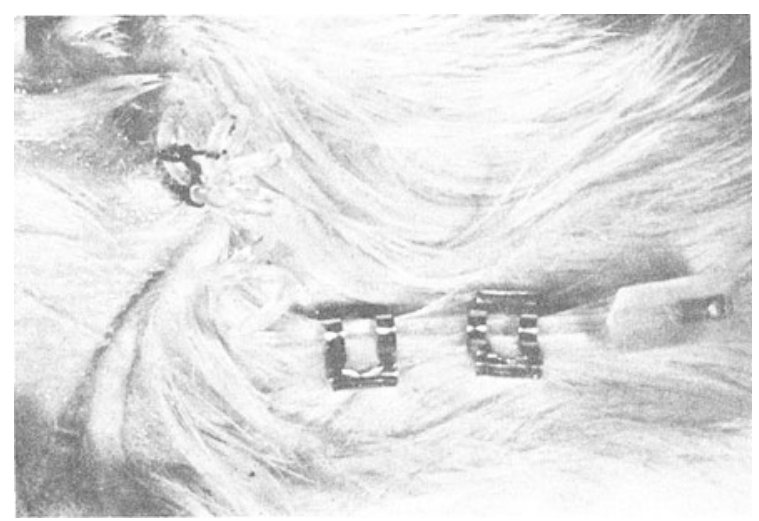

Figure 7. The cannula exits on the back of the neck just below the ears and on the midline. It is tied into the neck and the cannula is clipped to the rat's back with wound clips. The rat's head is at the left.

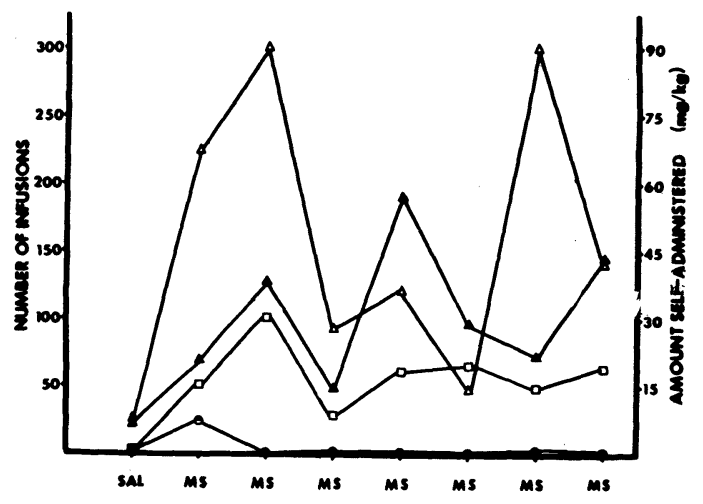

Figure 8. The number of infusions (right ordinate) and amount of drug self-administered in $\mathrm{mg} / \mathrm{kg}$ (left ordinate) for four rats during 10-h sessions with access to either saline (sal) or morphine sulfate (MS) solutions by the intragastric route.

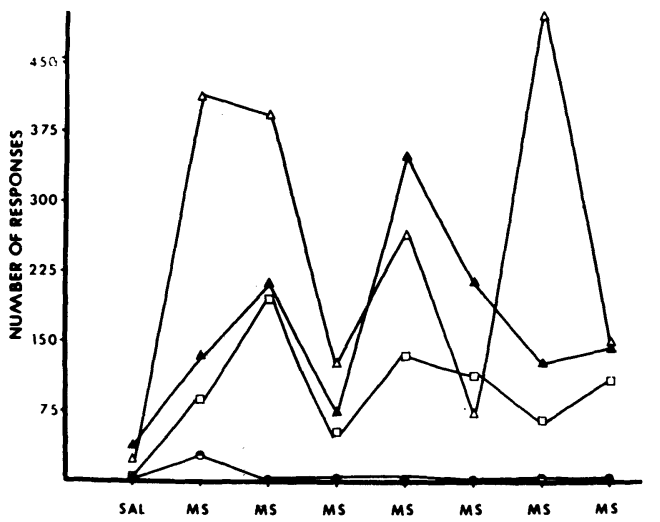

Figure 9. The number of responses emitted during access to saline (sal) and morphine sulfate (MS) solutions for four rats during 10-h sessions. 


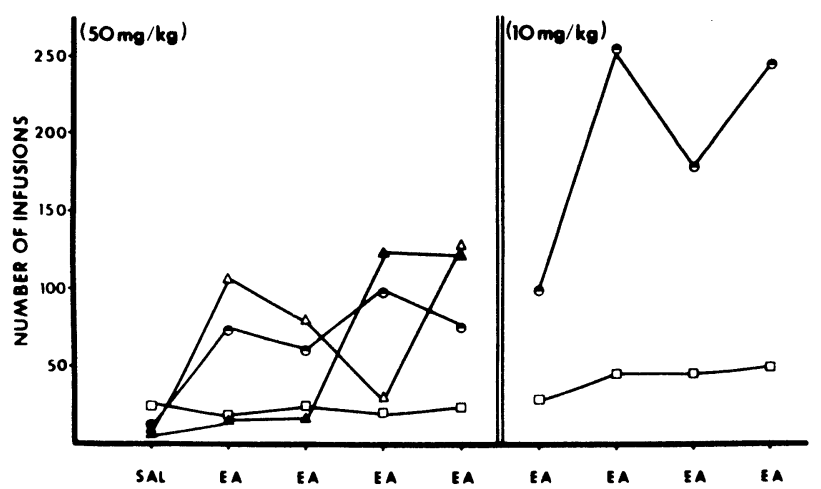

Figure 10. The number of infusions for four rats during 10-h sessions with access to saline (sal), $50 \mathrm{mg} / \mathrm{kg} /$ injection ethyl alcohol (EA) or $10 \mathrm{mg} / \mathrm{kg} /$ injection EA for two of the four rats.

$10 \mathrm{mg} / \mathrm{kg} /$ injection resulted in a large increase in both parameters for one subject and slight increases for the other.

Another important finding was that the cannulas in these rats remained effective for up to 4 months. They had not deteriorated at that time, but the animals were sacrificed to be examined for possible irritation or any other pathology resulting from cannulation. No abnormalities were observed, either in these animals sacrificed at 4 months or in others examined at various intermediate intervals (i.e., 1, 2, 4, and 8 weeks; $\mathrm{N}=4$ /group).

\section{DISCUSSION}

Research on the acquisition of self-initiated opiate-taking behavior by naive organisms has, to a large extent, employed the intravenous self-administration technique (Smith \& Davis, 1975). Such work has demonstrated that both naive monkeys (Deneau,

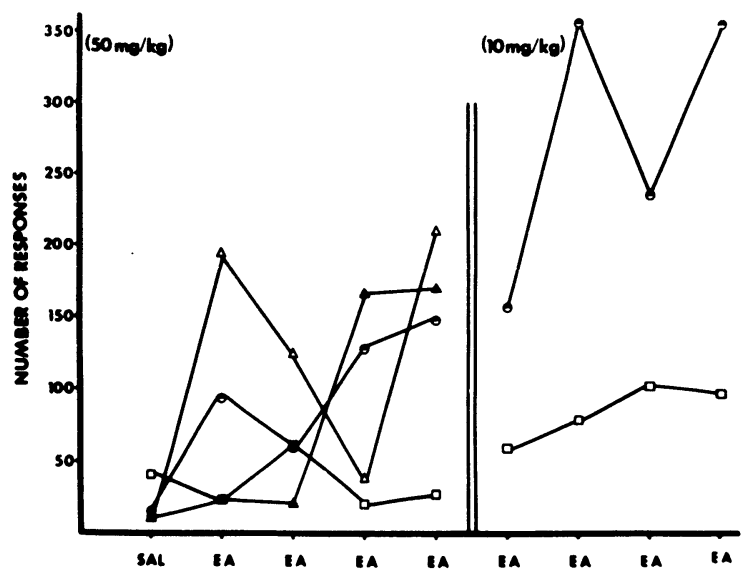

Figure 11. The number of responses emitted during access to saline (sal), $50 \mathrm{mg} / \mathrm{kg} /$ injection ethyl alcohol (EA) or $10 \mathrm{mg} / \mathrm{kg} /$ injection of EA.
Yanagita, \& Seevers, 1969; Woods \& Schuster, 1968) and naive rats (e.g., Davis \& Smith, 1972, 1973, 1974, 1975; Smith \& Davis, 1973, 1974a; Weeks \& Collins, 1971) will develop opiate self-administration behavior. To a similar but considerably lesser extent, alcohol self-administration by the intravenous route has also been studied in drug-naive organisms. Both naive monkeys (Deaneau, Yanagita, \& Seevers, 1969; Woods, Ikomi, \& Winger, 1971) and naive rats [Smith \& Davis (1974b); Smith, Werner, \& Davis (1975; Note 2, Note 3)] have been demonstrated to self-administer alcohol intravenously.

While the researches cited above demonstrate the value of an animal model employing the intravenous infusion of drugs, the new transesophageal intragastric infusion technique affords an advantageous alternative for the analysis of drug self-administration. It avoids problems associated with aversion to the oral sensory properties of the drug solution as well as postoperative problems associated with the abdominal and nasopharyngeal methods for intragastric infusion. Specifically, the abdominal approach requires an abdominal incision, an incision in the stomach wall, and the inserting of a plastic anchor button (or other anchor material) with an attached cannula before closing the wounds. Postoperatively, the abdominal method has the disadvantages of: (1) stomach-related infection and leakage (Kissileff, 1972); (2) possibility of severe gastric hemorrhage and/or gastric ulceration (Smith, Werner, \& Davis, Note 1); (3) lengthy postoperative recovery required to avoid death from gastric hemorrhage (7 days reported by Gotestam, 1973; 7 to 12 days according to our observations).

In the case of the nasopharyngeal approach, a permanent cannula attachment to the skull is made, and then the cannula is passing subcutaneously from the midline of the head down to nostril. It is then threaded through the nasopharynx, into the esophagus, and down to the stomach. Problems encountered with this technique include: (1) tissue irritation; (2) painful subcutaneous swelling on the head; (3) infection; (4) excessive sniffing, sneezing, and unusual respiratory patterns (J. R. Weeks, Note 4; Smith, Werner, \& Davis, Note 1). 1

Other data not included here indicate that higher doses of morphine (.5 to $10 \mathrm{mg} / \mathrm{kg} /$ injection) and drugs from other classes, $d$-amphetamine and barbiturates, also are self-administered by the IG route. It is clear that the esophageal approach provides an IG method which can be employed for the analysis of drug self-administration behavior.

\section{REFERENCE NOTES}

1. Smith, S. G., Werner, T. E., \& Davis, W. M. Intragastric self-administration of abuse drugs by rats. Paper presented at Southeastern Psychological Association meeting, Hollywood, Florida, May 1974. 
2. Smith, S. G., Werner, T. E., \& Davis, W. M. The intravenous self-administration of alcohol in the rat. Paper presented at Southeastern Psychological Association meeting, Hollywood, Florida, May 1974

3. Smith, S. G., Werner, T. E., \& Davis, W. M. Morphine and ethanol: Intragastric and intravenous self-administration. Paper presented at Society for Neuroscience, St. Louis, October 1974.

4. J. R. Weeks, personal communication, 1974 .

5. Werner, 1974, unpublished.

6. Yanagita, T., Ando, K., Takahashi, S., \& Ishida, $K$ Self-administration of barbiturates, alcohol (intragastric), and CNS stimulants (intravenous) in monkeys. Paper reported to the Committee on Problems of Drug Dependence, Palo Alto, California, February 1969.

\section{REFERENCES}

Davis, W. M., \& Smith, S. G. Alpha-methyltyrosine to prevent self-administration of morphine and amphetamine. Current Therapeutic Research, 1972, 14, 814-819.

Davis, W. M., \& Smith, S. G. Blocking of morphine based behavioral reinforcement by alpha-methylty rosine. Life Science, 1973, 12, 185-191.

Davis, W. M., \& Smith, S. G. Noradrenergic basis for reinforcement associated with morphine action in nondependent rats. In J. M. Singh and $H$. Lal (Eds.) Drug addiction volume 3: Neurobiology and influences on behavior New York: Stratton Intercontinental Medical Book Corp.. 1974. Pp. 155-168.

Davis, W. M.. \& Smith, S. G. Conditioning techniques in the study of reinforcement mechanisms and the self-administration of dependence producing drugs. In $S$ Ehrenpreis and A. Neidle (Eds.), Methods in narcotic research. New York: Dekker, 1975.

Deneau, G., Y anagita, T., \& Seevers, M. H. Self-administration of psychoactive substances by the monkey Psychopharmacologia, 1969, 16, 30-48.

Epstein, A. N. Water intake without the act of drinking. Science, $1960,131,497-498$.

Epstein, A. N. Feeding without orophary ngeal sensations. In $\mathbf{M}$ $R$. Kare and $O$. Maller (Eds.), The chemical senses and nutrition. Baltimore: Johns Hopkins Press, 1967.

Gotestam, K. G. Intragastric self-administration of medazepam in rats. Psy chopharmacologia, 1973, 28, 87-94.

Kissileff, H. R. Manipulation of the oral and gastric environments. In R. D. Myers (Ed.), Methods in psychobiology. New York: Academic Press, 1972.

Kohn, M. Satiation of hunger from food injected directly into the stomach versus food ingested by mouth. Journal of Comparative and Physiological Psychology, 1951, 44, $412-422$.

Kumar, R., Steinberg, H., \& Stolerman, I. P. Inducing a preference for morphine without premedication. Nature, $1968,218,564-565$.
Kumar, R., \& Stolerman, I. P. Morphine dependent behavior in rats: Some clinical implications. Psychological Medicine 1973, 3, 225-237.

Marfaing-Jallat, P., Pruvost, M., \& Le Magnen, J. La consommation d ethanol par auto-administration intragastrique chez le rat. Journal de Phy siologie (Paris), 1974, $68,81-95$.

Mello, N. K. A review of methods to induce alcohol addiction in animals. Pharmacology Biochemistry and Behavior, 1972, 1 , 89-101.

Nichols, J. R., \& Davis, W. M. Drug addiction II. Variation of addiction. Journal of the American Pharmaceutical Association, Scientific Edition, 1959, 48, 259-262.

Nichols, J. R., Headlee, C. P., \& Coppock, H. W. Drug addiction I. Addiction by escape training. Joumal of the American Pharmaceutical Association, Scientific Edition, 1956, 45 , 788-791.

Smith, S. G., \& Davis, W. M. Behavioral control by stimuli associated with morphine self-administration. Behavioral Biology, 1973, 9, 777-780.

Smith, S. G., \& Davis, W. M. Punishment of amphetamine and morphine self-administration behavior. The Psychological Record, 1974, 24, 432-435. (a)

Smith, S. G., \& Davis, W. M. Intravenous alcohol self-administration in the rat. Pharmacological Research Communications, 1974, 6, 397-401. (b)

Smith, S. G., \& Davis, W. M. Opiate self-administration: A review of the behavioral analy sis of opiate dependence. In $H$. Lal and J. M. Singh (Eds.), A behavioral analy sis of drug dependence. New York: Futura Publishing Company, 1975.

Smith, S. G., Werner, T. E.. \& Davis, W. M. Intravenous drug self-administration in rats: Substitution of ethyl alcohol for morphine. The Psychological Record, 1975, 25, 17-20.

Weeks, J. R., \& Collins, R. J. Primary addiction to morphine in rats. Federation Proceedings, 1971, 30, 277.

Wikler, A. Conditioning factors in opiate addiction and relapse. In D. W. Wilner and G. G. Kassebaum (Eds.), Narcotics. New York: McGraw-Hill, 1965.

Woods, J. H., Ikomi, F., \& Winger, G. D. The reinforcing property of ethanol. In M. K. Roach, W. M. McIssac, and P. J. Creaven (Eds.), Biological aspects of alcohol. Austin: University of Texas Press, 1971 .

Woods, J. H., \& Schuster, C. R. Reinforcement properties of morphine, cocaine, and spa as a function of unit dose. The International Journal of the Addictions, 1968, 3, 231-237.

\section{NOTE}

1. Most problems associated with the nasopharyngeal approach are observed both in acute and chronic settings.

(Received for publication October 18, 1974; revision accepted January 30,1975 .) 